\title{
NANOLEAKAGE EVALUATION OF NANO-FILLED RESIN COMPOSITE USING DIFFERENT ADHESIVE SYSTEMS AT DIFFERENT DENTIN DEPTH (AN INVITRO STUDY)
}

\author{
Hesham Monsef Nour Eldeen`*, Khaled Mohamed Noaman**, Mohamed Ahmed Wakwak***
}

\begin{abstract}
Objective: This study evaluated the nanoleakage of nano-filled resin composite using different adhesive systems at different dentin depth. Material and Methods: A total of 120 freshly extracted human molars were used in this study. The selected teeth were randomly divided into two main groups according to adhesive system(self-etch and total etch), each main group were divided in to two groups according to dentin depth(superficial and deep dentin), each group were divided in to 3 sub-groups according to storage periods(24hours, 3 months and 6 months). All the prepared cavities were restored incrementally using the nanofilled resin composite, then the specimens were immersed into silver nitrate and sectioned. Nanoleakage was measured. Results: The results showed that there was no statistically significant difference between self-etch and total etch according to the effect of adhesive system nor dentin depth on nanoleakage, while there was a statistically significant increase in median nano-leakage scores from 24 hours to 3 months as well as from 3 to 6 months of storage time. Conclusion: Usage of total etch or self-etch bonding agents has a positive effect on decreasing resin composite leakage. In deep dentin, it is advisable to use self etch bonding agents, while using total etch is indicated for deep dentin.
\end{abstract}

KEYWORDS: Self-etch, total etch, nanofilled resin composite, nanoleakage

\section{INTRODUCTION}

Resin composites were introduced as aesthetic materials for anterior restorations and their use was quickly extended to posterior teeth ${ }^{(1)}$. Despite evolution and the adhesive systems improvement, composite restorations still present some drawbacks $^{(2)}$. One of the major drawbacks is polymerization shrinkage, which leads to polymerization stress generation that cause debonding between tooth structure and resin composite that can reduce restoration longevity ${ }^{(3)}$. The incomplete penetra- tion of resin within the dentin micropores which in turn compromises the bonding synergism leading to bacterial leakage and ultimately lead to marginal discoloration, secondary caries and pulpal affection and it is different from microleakage as the composite shrinkage, creates stresses within the material at the tooth structure interface ${ }^{(4)}$.

Many efforts have been made to overcome this polymerization shrinkage, nanotechnology is one of them that can improve this continuity between the tooth structure and the nano-sized filler particle

\footnotetext{
* Masters Candidate, Dentist at Ministry of Health

** Professor and Head, Department of Operative Dentistry, Faculty of Dental Medicine, Boys, Cairo, Al-Azhar University

*** Lecturer, Department of Operative Dentistry, Faculty of Dental Medicine, Boys Cairo, Al-Azhar University

-Corresponding author: heshammonsef9@gmail.com
} 
and provide a more stable and natural interface between the mineralized hard tissues of the tooth and these advanced restorative biomaterials ${ }^{(5)}$. Nanocomposites have improved compressive strength, diametrical tensile strength, fracture resistance, low polymerization shrinkage and better aesthetics ${ }^{(6)}$.

Nanocomposites show greater fracture toughness and adhesion to tooth structure and may provide resins composite with a dramatically smaller filler particle size that can be loaded in higher concentrations which contains nanomers and nanoclusters ${ }^{(7)}$. The nanomers particles are 5 to $75 \mathrm{~nm}$, nanoclusters with zirconia/silica nanoparticles (5 to $20 \mathrm{~nm}$ in size) fused together at contact point, and the resulting porous structure is infiltrated with silane and glass fillers nanoparticles ${ }^{(8) .}$

There are two adhesive techniques are used generally in restorative dentistry. The first, etch and rinse technique includes etching with phosphoric acid and its meticulous rinsing, whereas, the second, self-etch technique excludes phosphoric acid and requires the mild acidic primers application for etching and chemical bonding to hydroxyapatite ${ }^{(9)}$. Good adaptation of composite restorations to dental tissue is achieved when there is no a marginal micro gap around the filling with sufficiently deep penetration of the composite resin into the tissues. Polymerization contraction during the hardening of the composite resin leads to the formation of micro gaps around composite fillings ${ }^{(10)}$. The purpose of this study was to evaluate the nanoleakage of nanofilled resin composite using two adhesive systems at different dentin depth.

\section{MATERIALS AND METHODS}

One type of resin composite (Filtek ${ }^{\mathrm{TM}}$ Z350 XT 3M Universal Restorative shade A3), two adhesive systems: self-etch adhesive system (Single bond ${ }^{\mathrm{TM}}$ 3M Universal Adhesive) and total etch adhesive system (AdperTM 3M Single Bond Plus Adhesive) were used in this study.

\section{Selection and Grouping of teeth:}

A total of 120 freshly extracted human molars age range 25 to 40 years were used in this study, the extracted teeth were collected from the outpatient clinic of oral and maxillofacial surgery department, Al Azhar University (boys) for periodontal or orthodontic reasons. The teeth were selected to be used in the study are divided into; cavities restored with Z350XT bonded by self-etch adhesive system and cavities restored with Z350XT bonded by total etch adhesive system. Each main group was divided into two subgroups $(n=30)$ according to dentin depth: superficial and deep dentin. Each subgroup was further subdivided according to storage period into one day, three months and six months storage period.

\section{Cavity preparation:}

Class V cavities were prepared (4 $\mathrm{mm}$ mesiodistal, $3 \mathrm{~mm}$ occluso-gingival and $2 \mathrm{~mm}$ or $2.5 \mathrm{~mm}$ depth) by using a carbide bur size \#014 (EMIL LANGE, Germany) with high-speed headpiece under copious amount of water, whereas the occlusal margin will be on enamel, while the gingival margin $1 \mathrm{~mm}$ above the CEJ. The depth of the cavity was determined by a precise digital caliber. No bevels were made at any of the enamel margins of the prepared cavities. A new bur was used after each 5 preparations.

\section{Adhesive system application and tooth restoration:}

In the first group $\left(\mathrm{A}_{1}\right)$ Single bond universal adhesive system was applied to the prepared cavities in a rubbing motion for 20 seconds with disposable applicator according to manufacturer's instructions. The excess solvent was removed by gentle air drying for 5 seconds until there was no movement of the adhesive film and the surface should maintain a uniform glossy appearance. The adhesive then was cured for 20 seconds according to the manufacturer's instructions with a LED curing unit at light intensity $1200 \mathrm{~mW} / \mathrm{cm}^{2}$ in standard mode (3M ESPE Elipar ${ }^{\mathrm{TM}}$ S10 U.S.A.). 
In the second group (A 2 ) the (single bond plus). Selective etching technique was used; the enamel surface was etched for 30 seconds by $37 \%$ phosphoric acid, while the rest of the cavity was etched for 15 seconds as recommended by manufacturer's instructions, then rinsed thoroughly with water for 10 seconds. Gently air dried to remove excess water without over dryness in a way that moist condition of the dentin was preserved.

Bonding agent was applied to the cavity by using fully saturated micro-brush with rubbing motion for 15 seconds and was gently air dried for 5 seconds approximately $0.5 \mathrm{~mm}$ away from the prepared surface. Then cured using light curing unit for 20 $\mathrm{s}$ according to the manufacturer's instructions. The light intensity was checked every 10 cases to ensure same light intensity by radiometer to check that the intensity is $1200 \mathrm{~m} \mathrm{~W} / \mathrm{cm} 2$.

All the prepared cavities were restored incrementally using the nanofilled resin composite (Filtek ${ }^{\mathrm{TM}}$ Z350 XT Universal Restorative) (3M ESPE). The material was placed in oblique incremental technique. Gold plated condenser was used to avoid sticking of composite to the instrument, each increment was cured for $40 \mathrm{sec}$. according to the manufacturer's instructions.

\section{Preparation of samples for microleakage evaluation:}

The sectioning was performed using a diamond disc of $4 \mathrm{~cm}$ diameter $\times 0.3 \mathrm{~mm}$ thickness with diamond cutting blades and water-resistant titanium coating with low speed saw, then the specimens were stored in distilled water until subjected to the microleakage evaluation. Microleakage pattern was observed under Stereo-microscope and evaluated qualitatively by the use of scores as described by Khera and Chan ${ }^{(11)}$ as follows:

- 0 - No leakage of the evaluated area

- $\quad 1-0.5 \mathrm{~mm}$ of the evaluated area
- $\quad 2-1 \mathrm{~mm}$ of the evaluated area

- $\quad 3-1.5 \mathrm{~mm}$ but not extended to axial wall

- 4-2 mm and extended to axial wall

Evaluation by SEM was done for one of random representative sample from each group.

Nano-leakage scores were analyzed as nonparametric data. Data were presented as median, range, mean and standard deviation values. MannWhitney $\mathrm{U}$ test was used to compare between the two adhesive systems as well as the two margins. Wilcoxon signed-rank test was used to compare between superficial and deep dentin. KruskalWallis test was used to compare between the three time periods. Dunn's test was used for pair-wise comparisons when Kruskal-Wallis test is significant. The significance level was set at $\mathrm{P} \leq 0.05$. Statistical analysis was performed with IBM SPSS Statistics for Windows, Version 23.0. Armonk, NY: IBM Corp.

\section{RESULTS}

\section{Effect of adhesive systems on leakage of resin composite:}

There was no statistically significant difference between nano-leakage scores of the two adhesive systems whether at superficial dentin at 24 hours of storage time $(\mathrm{P}$-value $=1.000$, Effect size $=$ $0.000)$ or deep dentin (P-value $=0.513$, Effect size $=0.335$ ). At 3 months of storage time there was no statistically significant difference between nanoleakage scores of the two adhesive systems whether at superficial dentin $(\mathrm{P}$-value $=0.093$, Effect size $=$ $0.951)$ or deep dentin $(\mathrm{P}$-value $=0.549$, Effect size $=0.335$ ). And at 6 months there was no statistically significant difference between nano-leakage scores of the two adhesive systems whether at superficial dentin $(\mathrm{P}$-value $=0.811$, Effect size $=0.132)$ or deep dentin $(\mathrm{P}$-value $=0.575$, Effect size $=0.335)$ Table (1). 
TABLE (1) Descriptive statistics and results of Mann-Whitney U test for comparison between nano-leakage scores of the two adhesive systems after 24 hours:

\begin{tabular}{|c|c|c|c|c|c|}
\hline Dentin & & Self-etch & Total-etch & \multirow{2}{*}{ P-value } & Effect size (d) \\
\hline \multirow{2}{*}{ Superficial } & Median (Range) & $0(0-1)$ & $0(0-1)$ & \multirow{2}{*}{1.000} & \multirow{2}{*}{0.000} \\
\cline { 2 - 4 } & Mean (SD) & $0.4(0.55)$ & $0.4(0.55)$ & & \multirow{2}{*}{0.513} \\
\hline \multirow{2}{*}{ Deep } & Median (Range) & $1(0-1)$ & $1(0-1)$ & 0.335 \\
\cline { 2 - 4 } & Mean (SD) & $0.6(0.55)$ & $0.8(0.45)$ & \\
\hline
\end{tabular}

*: Significant at $P \leq 0.05$

Our study revealed that samples of resin composite bonded to superficial dentin using selfetch adhesive system scored the highest leakage mean value $(2.6 \pm 0.89 \mathrm{SD})$ at 6 months storage time but scored the lowest leakage mean value $(0.4$ $\pm 0.55 \mathrm{SD}$ ) recorded from resin composite samples bonded to superficial dentin at 24 hours storage time. However, leakage of resin composite bonded using total etch bonding agent ranged from the lowest mean value $(0.4 \pm 0.55 \mathrm{SD})$ for superficial dentin samples at 24 hours to the highest leakage value $(2.4 \pm 1.14 \mathrm{SD})$ which was recorded for both deep dentin and superficial dentin at 6 months storage time.

\section{Effect of dentin depth on nanoleakage:}

There was no statistically significant difference between nano-leakage scores of superficial and deep dentin at 24 hours storage time $(\mathrm{P}$-value $=0.564$,
Effect size $=0.258$ ), Similarly; with total-etch; at 24 hours storage time, there was no statistically significant difference between nano-leakage scores of superficial and deep dentin (P-value $=0.157$, Effect size $=0.632$ ). At 3 months with self-etch; there was no statistically significant difference between nano-leakage scores of superficial and deep dentin $(\mathrm{P}$-value $=0.564$, Effect size $=0.258)$. Similarly, with total-etch; there was no statistically significant difference between nano-leakage scores of superficial and deep dentin (P-value $=0.059$, Effect size $=0.845)$. For 6 months storage time with self-etch; there was no statistically significant difference between nano-leakage scores of superficial and deep dentin (P-value $=0.083$, Effect size $=0.775)$, similarly; with total-etch; there was no statistically significant difference between nanoleakage scores of superficial and deep $(\mathrm{P}$-value $=$ 1.000, Effect size $=0.000$ ), Fig. (1).

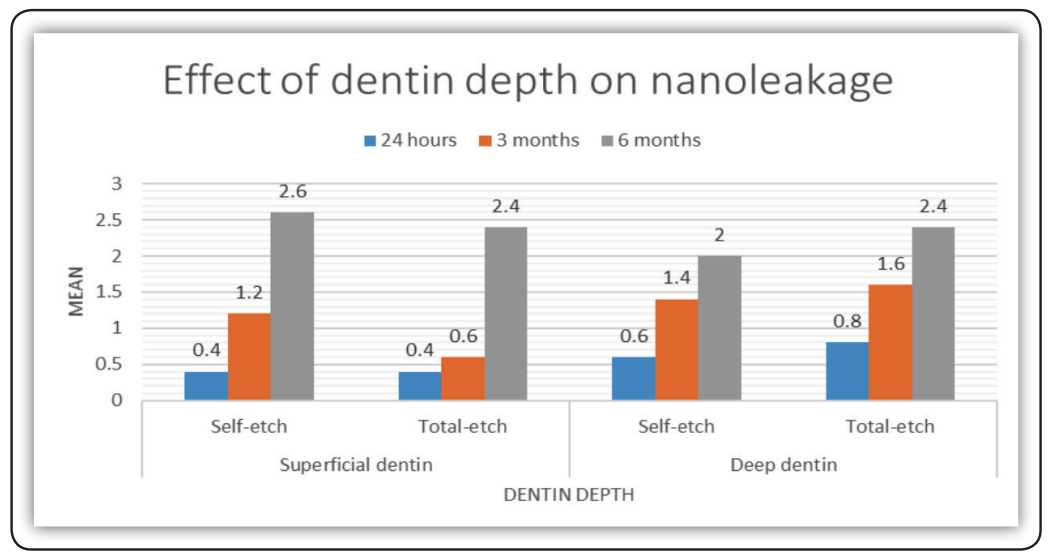

FIG (1) Chart showing the effect of dentin depth on nanoleakage. 


\section{Effect of storage times on nanoleakage:}

With self-etch adhesive system whether regarding superficial or deep dentin; there was a statistically significant difference between different time periods $(\mathrm{P}$-value $=0.004$, Effect size $=$ $0.746)$ and $(\mathrm{P}$-value $=0.023$, Effect size $=1.866)$, respectively. Pair-wise comparisons between the time periods revealed that there was a statistically significant increase in median nano-leakage scores from 24 hours to 3 months as well as from 3 to 6 months. Table (2). With total etch adhesive system regarding superficial dentin; there was a statistically significant difference between different time periods $(\mathrm{P}$-value $=0.006$, Effect size $=0.694)$.

TABLE (2) Descriptive statistics and results of Kruskal-Wallis test for comparison between nano-leakage scores at different time periods with self-etch system

\begin{tabular}{|c|c|c|c|c|c|c|}
\hline Dentin & & 24 hours & 3 months & 6 months & P-value & $\begin{array}{c}\text { Effect size } \\
\text { (Eta-squared) }\end{array}$ \\
\hline \multirow[t]{2}{*}{ Superficial } & $\begin{array}{l}\text { Median } \\
\text { (Range) }\end{array}$ & $0(0-1)^{C}$ & $1(1-2)^{\mathrm{B}}$ & $2(2-4)^{A}$ & \multirow[t]{2}{*}{$0.004 *$} & \multirow[t]{2}{*}{0.746} \\
\hline & Mean (SD) & $0.4(0.55)$ & $1.2(0.45)$ & $2.6(0.89)$ & & \\
\hline \multirow[t]{2}{*}{ Deep } & $\begin{array}{l}\text { Median } \\
\text { (Range) }\end{array}$ & $1(0-1)^{C}$ & $1(1-2)^{B}$ & $2(1-3)^{A}$ & \multirow[t]{2}{*}{$0.023^{*}$} & \multirow[t]{2}{*}{1.866} \\
\hline & Mean (SD) & $0.6(0.55)$ & $1.4(0.55)$ & $2(0.71)$ & & \\
\hline
\end{tabular}

*: Significant at $P \leq 0.05$, Different superscripts in the same row are statistically significantly different

\section{Scanning electron microscope study:}

\section{Effect of 24 hours of storage time on nanoleakage:}

Resin tags in total etch group showing silver nitrate particles that represents nanoleakage. Superficial dentin showing less nanolekage while deep dentin showing more nanoleakage Fig. (2).

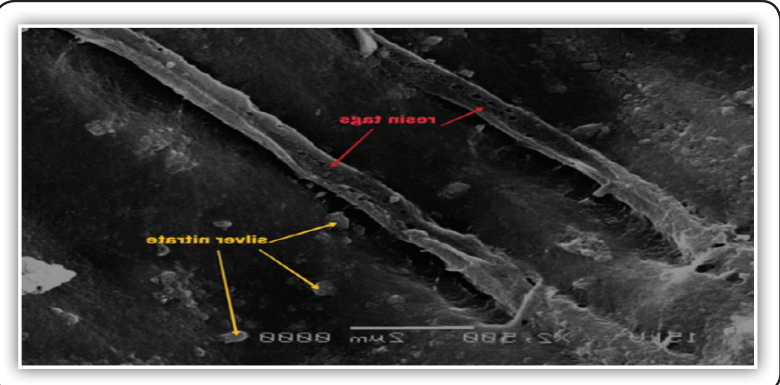

FIG (2) SEM photomicrograph of total etch group at superficial dentin showing hybrid layer and resin tags at (24) hours.

\section{Effect of 3 months of storage time on nanoleakage:}

Silver nitrate particles in self-etch group dispersed in the superficial and deep dentin that represents more nanoleakage Fig. (3).

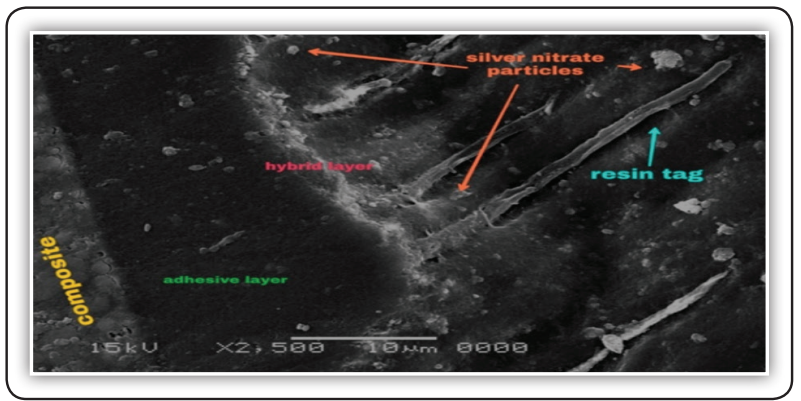

FIG (3) SEM photomicrograph of self-etch group at deep dentin hybrid layer showing resin tags at (3) months. 


\section{Effect of 6 months of storage time on nanoleakage:}

SEM of superficial dentin using self-etch showing nano-gaps between dentinal tubules and resin tags Fig. (4).

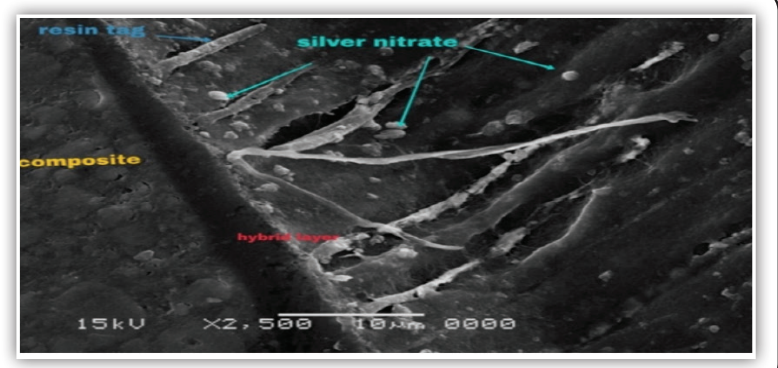

FIG (4) SEM photomicrograph of self-etch group at superficial dentin showing nanogaps between dentinal tubules and resin tags at (6) months.

\section{DISCUSSION}

In this study, cavities class $\mathrm{V}$ were chosen as they are ideal regarding leakage testing. There's no macro-mechanical undercuts present, requiring at least $50 \%$ of dentin bonding ${ }^{(12)}$. Nano filled resin composite (Filtek Z350 XT) was used in our study has a forming of nanocluster in a broad range of sizes enabling a high filler loading hence high strength and wear resistance, and it was used since filler technology might significantly influence the dental composite performance ${ }^{(13)}$. Total-etch technique was applied because a phosphoric acid etching step is utilized to modify both the dentin and enamel surfaces allowing adhesives penetration into the tooth surfaces ${ }^{(14)}$. Self-etch technique utilize the acidic adhesive that demineralize and penetrate the surface simultaneously ${ }^{(15)}$.

Silver nitrate migrates easily in the interface due to its tiny sized diameter molecule. This small size and high reactivity to stain after binding tightly to any exposed collagen fibrils that are not enveloped by the adhesive resin makes the sliver nitrate the most appropriate agent to detect the nanoporosities within the hybrid layer ${ }^{(16)}$.
Our result revealed that the highest leakage mean value score was for those resins composite samples bonded to superficial dentin using self-etch adhesive system at 6 months storage time that was confirmed by scanning electron microscope. Leakage spaces was found at hybrid layer interface, because it contains an acidic monomer and hydroxymethylmethacrylate which makes these polymers very hydrophilic and absorb water into the dentin interface and act even after polymerization as semipermeable membranes. This means increased silver uptake into the hybrid and adhesive layers resulting in higher amount of nano-leakage. This could be attributed to the fact that hybrid layer is porous somewhat, and is accessible to silver dye ${ }^{(17)}$.

It was valuable to mention that the self-etch adhesive do not totally remove the smear layer or open all the tubules since the self-etching materials have higher $\mathrm{pH}$ values than that of totaletch adhesive systems, and self-etching materials are not rinsed away, thus, the smear layer are incorporated into the bonded layer. Furthermore, as the self-etch adhesive systems only modify the smear layer, the residual water may lead to incomplete polymerization of the adhesive, limiting resin-dentin bond quality ${ }^{(18)}$.

This result was in agreement with Hashimoto

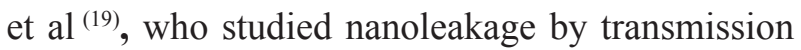
electron microscopy, and stated that; nanoleakage was observed in all the tested groups, but it was more pronounced for the self-etch adhesives when compared to the total-etch adhesives. The SEM finding also showed that the total etched dentin surfaces were continuously covered by the adhesive layer and sent very fine processes into the anatomizing tubules. This may be due to the specific characteristics of different adhesive systems that determine the amount of smear layer removal, demineralization of the underlying dentin, as well as the ability of the adhesive to wet and penetrate the dentin ${ }^{(20)}$. 
The difference in nanoleakage likely to be dependent on the dentin adhesive type used due to variable infiltration ability or difference in resin monomer composition or solvent. The selfetching adhesives are more hydrophilic than the total-etch adhesive systems and more permeable to water originated from dentin and therefore, more susceptible to degradation of resin-dentin bonds ${ }^{(21)}$.

This also came in agreement with Ulker et al. ${ }^{(22)}$, who found that the conventional total-etch adhesive systems tended to show less nanoleakage than the self-etch adhesives when they used the field emission-SEM (FE-SEM). Results are not in agreement with Zidan ${ }^{(23)}$ who concluded that self-etch adhesive systems resulted in the least penetration of silver nitrate hybrid layer as they have the potential to form a hybrid layer and seal dentin and the collagen fibrils.

Also the results were not in agreement with Souza et al ${ }^{(24)}$, who evaluated the effect of ethanol-wetbonding technique on dentin adhesive infiltration, by means of nanohardness, elastic modulus and nanoleakage and concluded that the use of universal adhesives is an alternative to create a stable bond. This could be attributed to the impregnation of the hydrophobic monomers in the dentin substrate decreases water amount of the interface, that would improve the hybrid layer characteristics at baseline and overtime ${ }^{(25)}$.

The greater leakage obtained using total etch (Single Bond plus) can also be explained by the fact that its bonding mechanism is based on the total removal of the smear layer following etching with phosphoric acid, which leaves an exposed collagen network available for primer impregnation ${ }^{(26)}$.This results came in agreement with Atash et $\mathrm{al}^{(27)}$, who concluded that self-etching adhesive system presented significantly lower values of leakage than did the Single Bond one-bottle system, either in the immediate assessment 24 hours or after 3 months of water storage.

\section{CONCLUSIONS}

Under the limitation of this study, the following conclusion was evident:

1. Self etch bonding agents has a positive effect on decreasing resin composite leakage

2. Using self-etch bonding with deep dentin is advisable agents to decrease leakage of resin composite.

3. Leakage of resin composite to is a time dependent process.

\section{REFERENCES}

1. Chan KHS, Mai Y, Kim H, Tong KCT, Ng D, Hsiao JCM. Resin composites filling. Materials (Basel). 2010; $3: 1228-43$.

2. Cangul S, Adiguzel O. The Latest Developments Related to Composite Resins. Int Dent Res. 2017; 7(2):32.

3. Soares CJ, Faria-E-Silva AL, Rodrigues M de P, Fernandes Vilela AB, Pfeifer CS, Tantbirojn D, et al. Polymerization shrinkage stress of composite resins and resin cements - What do we need to know? Braz Oral Res. 2017; 31:49-63.

4. Labib LM, Nabih SM, Baroudi K. Nanoleakage evaluation of posterior teeth restored with low shrinkable resin composite- An invitro study. J Clin Diagnostic Res. 2016; 10(7):102-4.

5. Khurshid Z, Zafar M, Qasim S, Shahab S, Naseem M, AbuReqaiba A. Advances in nanotechnology for restorative dentistry. Materials (Basel). 2015; 8(2):717-31.

6. Deepika K, Hegde M, Hegde P, Bhandary S. An evalution of compressive strength of newer nanocomposite: An in vitro study. J Conserv Dent. 2011; 14(1):36.

7. Lyapina M, Cekova M, Krasteva A, Dencheva M, YanevaDeliverska M, Kisselova A. Physical Properties of Nanocomposites in Relation To Their Advantages. J IMAB Annu Proceeding (Scientific Pap. 2016; 22(1):1056-62.

8. Zhou W, Liu S, Zhou X, Hannig M, Rupf S, Feng J, et al. Modifying adhesive materials to improve the longevity of resinous restorations. Int J Mol Sci. 2019;20(3):1-20

9. Giannini M, Makishi P, Ayres APA, Vermelho PM, Fronza BM, Nikaido T, et al. Self-Etch adhesive systems: A literature review. Braz Dent J. 2015; 26(1):3-10. 
10. Al-Zain AO, Eckert GJ, Lukic H, Megremis S, Platt JA. Polymerization pattern characterization within a resinbased composite cured using different curing units at two distances. Clin Oral Investig. 2019; 23(11):3995-4010.

11. Walsh EL, Hembree JH. Microleakage at the gingival wall with four class $\mathrm{V}$ anterior restorative materials. J Prosthet Dent 1985; 54:370-2.

12. Burke FJT. A Randomised Controlled Trial of a Universal Bonding Agent at Three Years: Self Etch vs Total Etch. Eur J Prosthodont Restor Dent. 2017; 21(1):44-8.

13. Alencar MF, Pereira MT, De-Moraes MDR, Santiago SL, Passos VF. The effects of intrinsic and extrinsic acids on nanofilled and bulk fill resin composites: Roughness, surface hardness, and scanning electron microscopy analysis. Microsc Res Tech. 2020; 83(2):202-7.

14. Suda S, Tsujimoto A, Barkmeier WW, Nojiri K, Nagura Y, Takamizawa T, et al. Comparison of enamel bond fatigue durability between universal adhesives and two-step self-etch adhesives: Effect of phosphoric acid pre-etching. Dent Mater J. 2018; 37(2):244-55.

15. Aydın F, Demirel G, Bilecenoğlu B, Ocak M, Gür G. Effect of different artificial aging protocols on marginal sealing ability of self-etch dental adhesives: micro-computed tomography evaluation. J Adhes Sci Technol. 2020; 34(4):388-99.

16. Cavalli V, Sebold M, Shinohara MS, Pereira PNR, Giannini M. Dentin bond strength and nanoleakage of the adhesive interface after intracoronal bleaching. Microsc Res Tech. 2018; 81(4):428-36.

17. Ali RH, Niazy MA, Naguib EA, Abdel Ghany OS. Effect of application technique and mode of curing on nanoleakage of universal adhesive system. Futur Dent J. 2018; 4(2):253-61.
18. Thanatvarakorn O, Prasansuttiporn $\mathrm{T}$, Thittaweerat $\mathrm{S}$, Foxton RM, Ichinose S, Tagami J, et al. Smear layer-deproteinizing improves bonding of one-step self-etch adhesives to dentin. Dent Mater. 2018; 34(3):434-41.

19. Hashimoto M, Nagano F, Endo K, Ohno H. A review: Biodegradation of resin-dentin bonds. Jpn Dent Sci Rev. 2011; 47(1):5-12.

20. Ahmeda AA, Mustafa M. Hassanb AIA. Microshear bond strength of universal adhesives to dentin used in total-etch and self-etch modes. Tanta Dent J. 2018; 15:91-8.

21. Tjäderhane L. Dentin bonding: Can we make it last? Oper Dent. 2015; 40(1):4-18.

22. Ulker M, Ulker HE, Karabekiroglu S, Botsali MS, Cetin AR. Effect of alternative modes of application on microleakage of one-step self-etch adhesives. J Dent Sci. 2013; $8(4): 425-31$.

23. Zidan A. Effect of chitosan on resin-dentin interface durability: a 2 year in-vitro study. ED.j. 2019;65:2955-65.

24. Souza MY De, Andrade JL, Marco T, Caneppele F, Bresciani E. Assessment of nanohardness, elastic modulus, and nanoleakage of the adhesive interface using the ethanolwet-bonding technique. Int J Adhes. 2020; 10:25-32.

25. Nagpal R, Manuja N, Pandit IK. Effect of ethanol wet bonding technique on the durability of resin- dentin bond with contemporary adhesive systems. J Clin Pediatr Dent. 2015;39(2):133-42.

26. Carrilho E, Cardoso M, Ferreira MM, Marto CM, Paula A, Coelho AS. 10-MDP based dental adhesives: Adhesive interface characterization and adhesive stability-A systematic review. Materials (Basel). 2019;12(5):1-18.

27. Atash Biz Yeganeh L, Seyed Tabai E, Mohammadi Basir M. Bonding Durability of Four Adhesive Systems. J Dent. 2015;12(8):563-70. 